\title{
A Proposal for An Air Quality Monitoring System for Cartagena de Indias
}

\author{
María José González Campo \\ School of Engineering \\ Universidad Tecnológica de Bolívar \\ Cartagena de Indias, Colombia 130010 \\ mgonzalez@utb.edu.co
}

\author{
Jairo Enrique Serrano Castañeda \\ School of Engineering \\ Universidad Tecnológica de Bolívar \\ Cartagena de Indias, Colombia 130010 \\ jserrano@utb.edu.co
}

\author{
Juan Carlos Martínez-Santos \\ School of Engineering \\ Universidad Tecnológica de Bolívar \\ Cartagena de Indias, Colombia 130010 \\ jcmartinezs@utb.edu.co
}

\begin{abstract}
This paper presents an Air Quality Monitoring System for the city of Cartagena de Indias. The goal of this system is to monitor the air quality in the city and to establish the current state of the air Cartagena's citizen breathe. Data is going to be acquired through a sensor network, and the information is going to be displayed on web or mobile application allowing access from anywhere in the world to anyone that may be interested. It is expected that the availability of this information allows research centers, educational institutions, and government to design plans for prevention and improvement of the air quality in the city based on historical and real-time data.
\end{abstract}

\section{INTRODUCTION}

According to the 2017 Cartagena's Quality of Life Report from "Cartagena Como Vamos" [1], it is not possible to establish the state of the environment in Cartagena, because there are no up-to-date measurements on both air and noise, which not only ratifies what was previously affirmed, but also the need for information to serve as a key instrument for making quick and timely decisions, as well as a key tool for the achievement of new projects for a city in constant growth.

Based on the Air Quality Diagnosis of Cartagena de Indias in 2014 and 2015, air quality in Cartagena was moderate at that time. For 2014 available information is insufficient in terms of concentration of pollutants. From the 11 monitoring equipments operating that year, just six of them had information availability equal to or greater than $75 \%$ of the annual data. Meanwhile, during 2015 the number of stations operating integrated to the Air Quality Monitoring System increased from four to five but none provided an amount equal to or greater than $75 \%$ of the total annual data. For those years, Cartagena's Air Quality Index for O3 indicated good air quality, for PM10 it is mostly a good air quality with isolated events where a moderated air quality was presented, and for PM2.5 a moderate air quality is reported and sometimes unhealthy for sensitive groups [2].

A 2016 report, Design of the Intelligent System of Environmental Quality Monitoring of Q artagena District, estimated that the Air Quality Index for the locations Bomba del Amparo, Peaje de Ceballos, and Maria Auxiliadora was, in all three cases, between Unhealthy for sensitive groups and Unhealthy. The highest concentrations of pollutants is located in high vehicular traffic sectors, such as Peaje Ceballos and Bomba del Amparo [3].

Digital Object Identifier (DOI):

http://dx.doi.org/10.18687/LACCEI2019.1.1.280

ISBN: 978-0-9993443-6-1 ISSN: 2414-6390
However, correlation can not be determined due to the fact that the points, time-frames and periodicity of monitoring are not comparable. The only thing that can be concluded is that in fact at this time there is not enough information to estimate the quality of the air that Cartagena's citizens breathe. There is also no information that could correlate the pollutants concentration levels with respiratory diseases.

In conclusion, there is no real-time or updated data about Air Quality for Cartagena or the Colombian Caribbean [4]. Therefore, an interdisciplinary research team was assembled to design a short term plan with the following goals: (i) to position Cartagena as the first city in the Caribbean and fourth in Colombia providing detailed real-time information regarding the Air Quality Cartagena'breatizen hs cit, (ii) to make the University XYZ the motor of this initiative, and (iii) to connect the current work on AquApp [5] regarding the quality of the internal swamps and lagoons system in the Bay of Cartagena.

The rest of the paper is structured as follows. Section II presents the design and implementation of our information system. Section III peesents the design and implementation of our sustainable plan. Section IV shows the methodology to use. Finally, Section V concludes the paper.

1. Partnership and networks
2. Mapping and sensor allocation
4. Equipment procurement
4. System testing
7. Commissioning

Fig. 1. Methodology of the project implementation

\section{INFORMATION SYSTEM}

Information systems are several for different envinonmental variables. However, water is the most monitored [6]. In reference to air, there are several approaches. AirSensEUR uses

17th LACCEI International Multi-Conference for Engineering, Education, and Technology: Industry, Innovation, And Infrastructure for Sustainable Cities and Communities, 24-26 July 2019, Jamaica. 
low cost sensors for regulatory purposes [7], the Making Sense H2020 CAPS Project made an analysis of high impact and sustainable examples of urban citizen and community centred sensing initiatives around the world [8] and other authors have also researched on the subject [9], [10], [11], [12], [13]. For public service purposes, there is The Smart Ring Experience, a smart sensor network in Italy [14]. However, the best example for air quality monitoring is Air Quality Index Project [4], which comprises real-time air quality information for more than 10,000 stations around the globe. Specifically in Colombia, the most relevant work is SIATA [15], an early warning system for Medellin and the Aburr Valley.

According to the World Air Quality Index parameters [4] and in order to provide information relevant for this index, the measures the system has to monitor are shown in Table I $]$ and Table II

\begin{tabular}{|l|l|}
\hline Variable & Description \\
\hline PM10 & Particulate Material 10um - large particles $\left(\mathrm{ug} / \mathrm{m}^{3}\right)$ \\
$\mathrm{PM} 2.5$ & Particulate Material 2.5um - small particles $\left(\mathrm{ug} / \mathrm{m}^{3}\right)$ \\
$\mathrm{SO}_{2}$ & Sulfur dioxide $\left(\mathrm{ug} / \mathrm{m}^{3}\right)$ \\
$\mathrm{NO}_{2}$ & Nitrogen dioxide $\left(\mathrm{ug} / \mathrm{m}^{3}\right)$ \\
$\mathrm{CO}$ & Carbon monoxide $\left(\mathrm{ug} / \mathrm{m}^{3}\right)$ \\
$\mathrm{O}_{3}$ & Tropospheric ozone $\left(\mathrm{ug} / \mathrm{m}^{3}\right)$ \\
\hline
\end{tabular}

TABLE I

AIR QUALITY PARAMETERS

\begin{tabular}{|l|l|}
\hline Variable & Description \\
\hline Temperature & ${ }^{\circ} \mathrm{C}$ \\
Relative Humidity & $\%$ \\
Atmospheric Pressure & $\mathrm{Pa}$ \\
Wind & $\mathrm{Km} / \mathrm{h}$ \\
\hline
\end{tabular}

TABLE II

Meteorological Parameters

As information system, AquApp is going to be used [16], which is a collaborative sensor network that collects information regarding the quality of the water bodies of the city of Cartagena. AquApp monitors the water bodies surrounding the city and establishes the current state of the water. The system determines the degree of pollution, water levels and environmental conditions of marine fauna and flora through a sensor network. At the same time, this sensor network can help detect contaminants such as oil, which can help take action quickly, reducing damage to the ecosystems. Fig. 2 shows the actual application.

Some adaptations are needed to connect the new Air Quality Sensor Network to AquApp and make that monitor system ready for air quality monitoring such as a new layer as shown in the Fig. 4 The general idea is to collect data from a sensor network and to show the different air indexes using a color scale legend (based on the World Air Quality Index [4]), following the standards: good, moderate, unhealthy for sensitive groups, unhealthy, very unhealthy, hazardous.

Following the original idea, the collected data will continue available to scientists and institutions for further analysis. The information can be acquired through a website, allowing access from anywhere in the world to anyone that may be interested. It allows research centers, educational institutions, and government to design plans for prevention and improvement of water bodies surrounding the city, and provide updated information.

For air quality, new sensors will be added across the city to cover all the sectors. The integration would be safe and faster. This is possible thanks to the RESTful API, which was designed to create and integrate new utilities and to allow a wider use of the data and to be able to deploy these changes in any application or device that consumes this information. The AquApp architecture, shown in Fig. 3, allows us to create services and applications that can be used by any device or client who understands HTTP. As a result, it is incredibly easy to add new devices for air quality monitoring.

\section{STUdy CASE}

Implementation of Sustainable Development Goals rather than adding value to the industry is a need for the nation to strength its economic development and a commitment with the international community. The National Planning Department stipulated the strategies to achieve said implementation, and environmental regulations at national levels are regulated in order to achieve sustainable development, Conpes 3918 [17]. An example of this is the Resolution 2254 of 2017 [18], which adopts the ambient air quality standard and promotes the management of air quality to protect human health and well-being in the framework of sustainable development.

In Cartagena, even though it is not possible to establish the state of the environment in the city because there are no air measurements [1], it is necessary and urgent to take measures in this regard if better results in the indicators of quality of life in the city are expected, as well as improving economic development and, consequently, urban indicators; and strengthening and breaking institutional barriers, such as, for example, deficiencies in information systems, monitoring and follow-up, and articulation between sectors [19], [20].

In the world and in Colombia itself, actions have already been taken in this direction, where different sectors of society are articulated to strengthen the information and monitoring systems of their territories (see SIATA case, scientific citizens [15]), through affordable tools to the communities and where it involves all citizens in the monitoring and empowerment of air quality in their region.

The University is an academic center that gathers an interdisciplinary team that allows identification and problem solving in an integral way. In the particular case of air quality in the city of Cartagena, the institution has expert investigative teachers in areas such as air quality, social development, information management from the new communication technologies, among others; and from which, and through this project, it intends to generate synergy between sectors in a joint work for the management of access to air quality information and baseline for making timely decisions for the sustainable development of the district.

17th LACCEI International Multi-Conference for Engineering, Education, and Technology: Industry, Innovation, And Infrastructure for Sustainable Cities and Communities, 24-26 July 2019, Jamaica. 


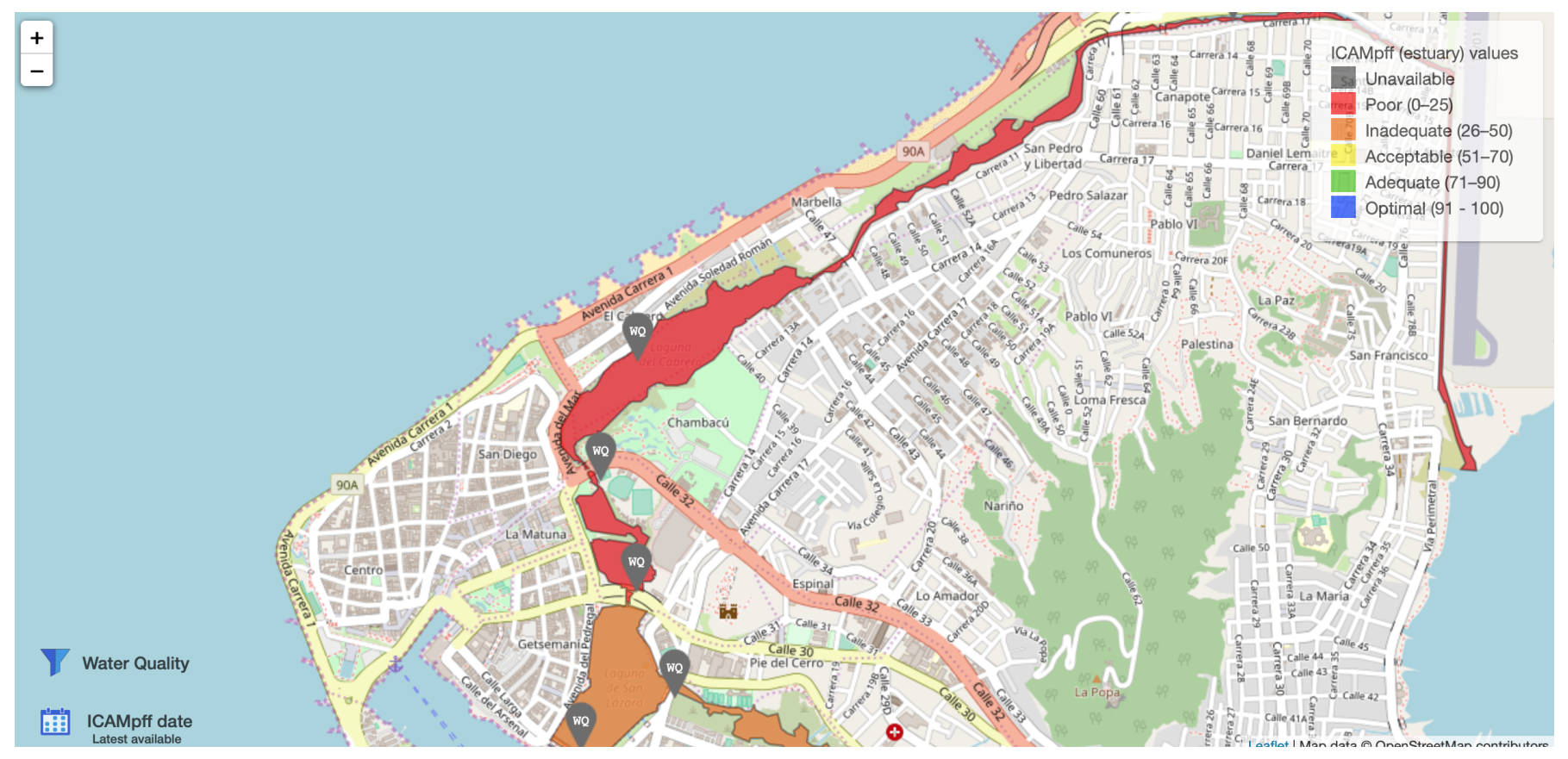

Fig. 2. AquApp user interface.

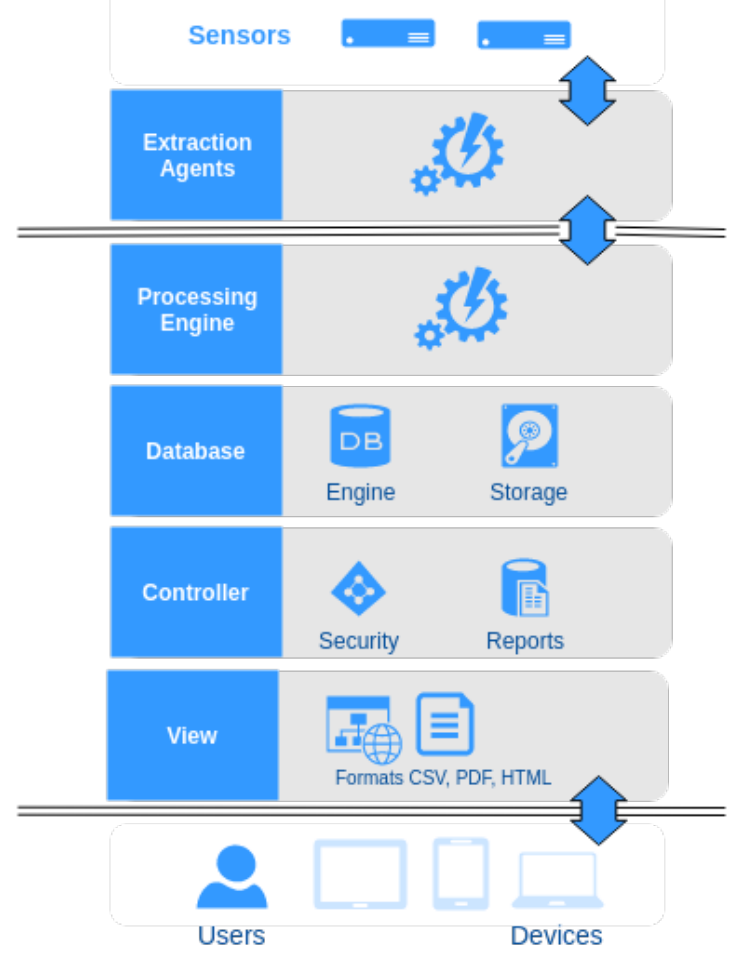

Fig. 3. AquApp's Platform Architecture.

\section{Methodology}

In this section are presented, concisely, the main steps for the achievement of the timely development of the project:

\section{A. Partnership and networks}

The project will be socialized to different sectors in the city, in order to establish alliances for its development. In the beginning, these alliances are focused on the following sectors:

1) Industrial: Support is seeked in this sector for its relevance in the development and impact in the region, acquisition of resources and project positioning.

Also support is required from companies that offer telecommunications infrastructure. For instance, there is already an agreement with one of them, that will provide connectivity for sensors and things throughout the fiber network distributed across the city.

2) $N G(D) O$ : This is a project for and with the community and pretends that they feel part of it. So, it looks to articulate networks with organizations that are working continuously with communities and contribute in the accurate incidence of the project.

3) Public Administration: This project seeks, through the generated information, public policies that take appropriate measures for the benefit of the environment and the communities. This is why it is relevant to make the government aware of the importance of having up-to-date information on air quality and articulated work with the academy in order to achieve those public policies in this area.

\section{B. Mapping and Sensor Allocation}

The purpose is to establish a sensors network that covers strategic points of the city, and is expected to draw an air quality integrated profile. Once this happens, information will be generated through georeferencing, which is going to be represented in the University web platform: AquApp. 


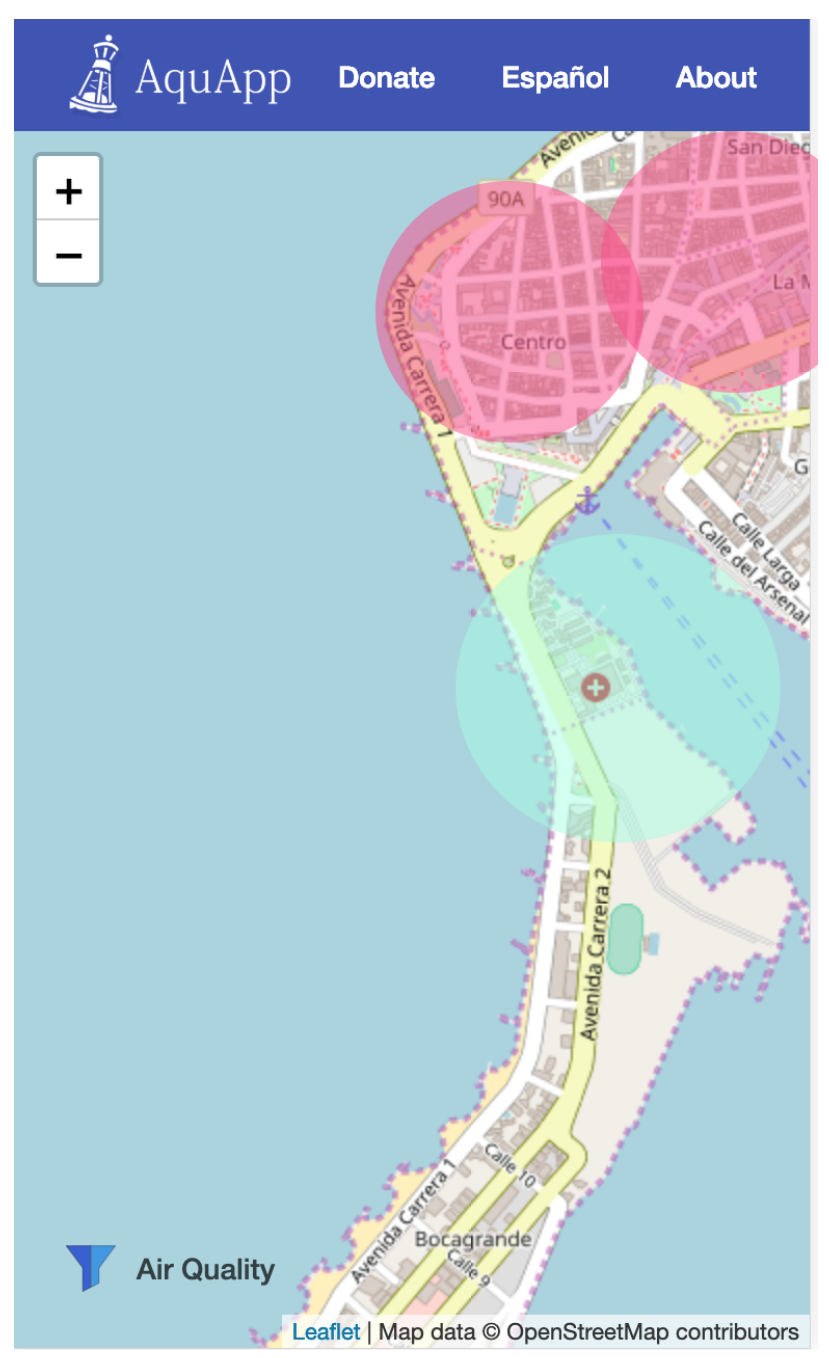

Fig. 4. Air Quality Layer in AquApp

\section{Equipment Procurement}

Select appropriate equipment for the environmental conditions in which the sensors will be located, considering that Cartagena is a hostile environment, in terms of salinity and humidity.

It is consider the use of IoT custom devices made with microcontroller boards (SoC) fabricated in University laboratory like [21] or [22] furthermore that turnkey specific devices made for it.

\section{System testing}

Once the nodes are deployed, the measurements delivered by the sensors must be validated with certified equipment. From this point the sensors and the monitoring measures must be calibrated; taking into account that this calibration process is continuous.

\section{E. Community Project Socialization}

After establishing strategic points, validating information and making the necessary adjustments, the project will be socialized with the citizens in order to empower them through this project, see it as their own, participate and support its development. Their participation in this stage of the project will be necessary to determine the sensors final location and hosts, which will be in a citizen place according to the strategic points established in the mapping.

\section{F. Training}

Once the citizen is selected to be part of the project, he/she will train in the following skills:

- Air quality and parameters monitored by the sensors.

- Operation.

- Maintenance and care.

- Energy supply and internet for its operation.

- Monitor alerts.

\section{G. Commissioning}

After the project commissioning, a data management will be carried out, with the aim of guaranteeing its confidentiality, integrity and availability, in order that whoever wants to review the data, can have the confidence that the information is objective and has not been manipulated by conflict of interests issues. The data will be open but safe.

\section{H. Validation}

A validation process will be carried out in determined periods in order to verify that the sensors are working properly, that the generated data is accurate and that the parameters and conditions are being developed according to the established project guidelines. It is important to make sure that the process fulfills the need of validated information supply, if the aim of the present proposal is to generate a positive impact on the development of the region through data generation.

\section{CONClusion}

The academical sector has to be active part of the construction of sustainable regions and the creation of platforms such as AquApp and SIATA Scientific Citizen in Colombia reflects not only the compromise but also the need to provide Air Quality data in a context of lax information in the city. This is going to be an academical tool thought from the citizenship for the citizens and build interdisciplinary work teams for the best future for Cartagena, but also from objective and validated data that sees towards the incorporation to national and international validation systems for Air Quality Index Monitoring.

A secondary goal of this project is to continue the work made with the academic community. The idea is to call for collaborators: government institutions and research centers as the $\mathrm{CIOH}$, the IDEAM (Instituto de Hidrología, Meteorología y Estudios Ambientales), even the ENAP (Escuela Naval de Cadetes Almirante Padilla) can use our platform and join forces in pro of Cartagena sustainability.

17th LACCEI International Multi-Conference for Engineering, Education, and Technology: Industry, Innovation, And Infrastructure for Sustainable Cities and Communities, 24-26 July 2019, Jamaica. 


\section{ACKNOWLEDGMENT}

The authors would like to thank University throughout G1 and $\mathrm{G} 2$ groups for their support on the development of base projects under the grants XXXX and YYYY on which they are built this new initiative.

\section{REFERENCES}

[1] Cartagena Como Vamos, "Informe de Calidad de Vida," http://www.cartagenacomovamos.org/nuevo/ecv/, Aug. 2018.

[2] a. Martnez Espeleta, Gustavo Rafael, "Diagnstico de la calidad del aire de la ciudad de cartagena de indias, 2014 y 2015 / gustavo rafael martnez espeleta ; directora mara elena huertas bolaos." 2016.

[3] Establecimiento Pblico Ambiental - EPA Cartagena, "Diseño del sistema inteligente de monitoreo de la calidad ambiental del distrito de cartagena," http://observatorio.epacartagena.gov.co/diseno-delsistema-inteligente-de-monitoreo-de-la-calidad-ambiental-del-distritode-cartagena/, 2016

[4] World Air Quality Index team, "World Air Quality Index," https://waqi.info, Aug. 2007.

[5] J. Castaneda, O. Patino, and J. Martinez-Santos, "AquApp, an information system for a collaborative sensor network," in 2016 IEEE 11th Colombian Computing Conference, CCC 2016 - Conference Proceedings, 2016.

[6] C. Contreras, J. A. Molina, P. Osma, and D. Zambrano, "Development of a system for the acquisition and remote transmission of water quality based on the internet of things (iot) for aquaculture," 2018.

[7] M. Gerboles, L. Spinelle, and M. Signorini, "Airsenseur: an open data/software/hardware multi-sensor platform for air quality monitoring. part a: sensor shield," Citeseer, Tech. Rep., 2015.

[8] M. Balestrini, T. D. Ladera, A. Pólvora, and S. Nascimento, "Deliverable."

[9] Q. Jiang, F. Kresin, A. K. Bregt, L. Kooistra, E. Pareschi, E. Van Putten, H. Volten, and J. Wesseling, "Citizen sensing for improved urban environmental monitoring," Journal of Sensors, vol. 2016, 2016.

[10] B. Mijling, Q. Jiang, D. d. Jonge, and S. Bocconi, "Field calibration of electrochemical no 2 sensors in a citizen science context," Atmospheric Measurement Techniques, vol. 11, no. 3, pp. 1297-1312, 2018.

[11] M. Rogulski and A. Badyda, "Application of the correction function to improve the quality of pm measurements with low-cost devices," in SHS Web of Conferences, vol. 57. EDP Sciences, 2018, p. 02009.

[12] G. Miskell, J. A. Salmond, and D. E. Williams, "Solution to the problem of calibration of low-cost air quality measurement sensors in networks," ACS sensors, vol. 3, no. 4, pp. 832-843, 2018.

[13] M. Mueller, J. Meyer, and C. Hueglin, "Design of an ozone and nitrogen dioxide sensor unit and its long-term operation within a sensor network in the city of zurich," Atmospheric Measurement Techniques, vol. 10, no. 10, pp. 3783-3799, 2017.

[14] M.-G. Villani, F. Cignini, F. Ortenzi, D. Suriano, and M. Prato, "The smart ring experience in laquila (italy): Integrating smart mobility public services with air quality indexes," Chemosensors, vol. 4, no. 4, p. 24 , 2016.

[15] A. Área Metropolitana del Valle de Aburrá, "Sistema de Alerta Temprana de Medellín y el Valle de Aburrá," https://siata.gov.co/sitio_web/index.php/home, 2018.

[16] J. E. S. Castañeda, O. A. Patino, and J. C. Martinez-Santos, "Aquapp, an information system for a collaborative sensor network," in 2016 IEEE 11th Colombian Computing Conference (CCC). IEEE, 2016, pp. 1-6.

[17] Departamento Nacional de Planeación, "Estrategia para La Implementación de los Objetivos de Desarrollo Sostenible en Colombia," https://colaboracion.dnp.gov.co/CDT/Conpes/Económicos/3918.pdf, Mar. 2018.

[18] Ministerio de Ambiente y Desarrollo Sostenible, "Resolución 2254 por la cual se adopta la norma de calidad de aire ambiental y se dictan otras disposiciones." http://www.minambiente.gov.co/images/normativa/app/resoluciones/, Nov. 2017.

[19] Programa de las Naciones Unidas para el Desarrollo, "Agenda 2030 Transformando Colombia," http://www.co.undp.org/content/colombia, May 2015.

[20] M. S. Herrero, "ODS en Colombia: Los retos para 2030," http://www.co.undp.org/content/colombia/es/home/library/ods/odsen-colombia-los-retos-para-2030.html, Jul. 2018.
[21] S. Kumar and A. Jasuja, "Air quality monitoring system based on IoT using Raspberry Pi," in 2017 International Conference on Computing, Communication and Automation (ICCCA), May 2017, pp. 1341-1346.

[22] G. Parmar, S. Lakhani, and M. K. Chattopadhyay, "An IoT based low cost air pollution monitoring system," in 2017 International Conference on Recent Innovations in Signal processing and Embedded Systems (RISE), Oct. 2017, pp. 524-528. 